\title{
Vehiculation of Methyl Salicylate from Microcapsules Supported on Textile Matrix
}

\author{
Samira Mendes ${ }^{1, *}$, André Catarino ${ }^{2}{ }^{(}$, Andréa Zille ${ }^{2}\left(\mathbb{C}\right.$, Nádia Fernandes $^{3}$ and Fabricio Maestá Bezerra ${ }^{1}(\mathbb{C}$ \\ 1 Textile Engineering, Federal University of Technology—Paraná, 635 Marcílio Dias St, Apucarana, \\ PR 86812-460, Brazil; fabriciom@utfpr.edu.br \\ 2 2C2T-Center for Textile Science and Technology, University of Minho, Campus de Azurém, \\ 4800-058 Guimarães, Portugal; whiteman@det.uminho.pt (A.C.); azille@det.uminho.pt (A.Z.) \\ 3 Department of Chemical Engineering, State University of Maringá, Colombo Avenue, \\ Maringá, PR 5790, Brazil; nadiareginacfm@hotmail.com \\ * Correspondence: samiramendes@utfpr.edu.br
}

check for updates

Citation: Mendes, S.; Catarino, A.; Zille, A.; Fernandes, N.; Bezerra, F.M. Vehiculation of Methyl Salicylate from Microcapsules Supported on Textile Matrix. Materials 2021, 14, 1087. https://doi.org/ma14051087

Received: 13 January 2020

Accepted: 11 February 2020

Published: 26 February 2021

Publisher's Note: MDPI stays neutral with regard to jurisdictional claims in published maps and institutional affiliations.

Copyright: (c) 2021 by the authors. Licensee MDPI, Basel, Switzerland. This article is an open access article distributed under the terms and conditions of the Creative Commons Attribution (CC BY) license (https:/ / creativecommons.org/licenses/by/ $4.0 /)$.

\begin{abstract}
In recent years, textile industries have focused their attention on the development of functional finishing that presents durability and, consequently, controlled release. However, in the case of methyl salicylate microcapsules supported on a textile matrix, studies indicate only the interactions between substrate and microcapsules and the drug delivery system, not applying the release equations. This study reports the mechanism and kinetics of controlled release of microcapsules of gelatin and gum Arabic containing methyl salicylate as active ingredient incorporated into textile matrices. According to the results presented, it was possible to verify that the wall materials participated in the coacervation process, resulting in microcapsules with well-defined geometry, besides promoting the increase of the thermal stability of the active principle. The samples $(100 \%$ cotton, CO, and $100 \%$ polyamide, PA) functionalized with microcapsules released methyl salicylate in a controlled manner, based on the adjustment made by the Korsmeyer-Peppas model, indicating a Fickian mechanism. The influence of temperature was noticeable when the samples were subjected to washing, since with higher temperature $\left(50^{\circ} \mathrm{C}\right)$, the release was more pronounced than when subjected to lower temperature $\left(37^{\circ} \mathrm{C}\right)$. The results presented in this study indicate that the mechanism of backbone release is influenced by the textile matrix and by the durability of the microcapsule during the wash cycles.
\end{abstract}

Keywords: textile; microcapsules; controlled release

\section{Introduction}

Drugs, essential oils and fragrances have been used as essential compounds in textile finishing, in order to meet the various requirements that the consumer presents today. Many of these chemical compounds are highly volatile, which may present a disadvantage in their application on the surface of the fabric, due to their rapid and uncontrolled release. Therefore, one of the main focuses of the textile industry is the production of finishing that has durability, that is, release the active ingredient in a controlled way, consequently leading to an increase in its life cycle [1].

Microencapsulation aims to coat active agents, protecting them from adverse environmental conditions, such as light, humidity, oxygen and other compounds, which could result in degradation or polymerization of the active agent [2,3]. There are several microencapsulation techniques that can be used to improve the stability of the active ingredients, such as simple or complex coacervation, fluidization, lyophilization and spray drying $[4,5]$. Among these techniques, complex coacervation is an alternative process, in which the ionic interaction between two polymers leads to the formation of coacervates and phase separation [6]. Such a technique can produce microcapsules applicable to the textile industry, due to the fact that they have resistance to temperature and have favorable characteristics for controlled release $[7,8]$. 
Some studies show the application of microcapsules in textile articles, as in the work of Lis et al. [9], Bezerra et al. [10] and Carreras et al. [11], indicating that microcapsules can be used as fabric finishing, increasing their functionality. The fabrics that become supports for the release of active ingredients are called biofunctional textiles. These can be defined as textile substrates that have been modified to attain new properties and added value [9]. Some examples of biofunctional textiles are antimicrobial and cosmetotextiles [12].

The advantages of using biofunctional textiles are a high area of contact with the skin, drug loading capacity, ease of application, low price, release by stimulation, biocompatibility and being non-allergic and non-toxic, among other properties [13-15]. Thus, the choice of the active principle is of importance to the desired effect of the fabric.

Methyl salicylate is a chemical compound widely used for treatments of musculoskeletal pain, such as athletic injuries, swelling, tension or torsion [16,17]. Generally, the treatment involves external application to the affected area of a drug that has methyl salicylate as its active ingredient. However, it has some drawbacks, such as low water solubility and dosage control, as well as high volatility [18-20]. This means that the concentration of methyl salicylate should be controlled to ensure effective delivery of the drug, in order to achieve anti-inflammatory and analgesic effects and, on the other hand, to ensure that there is no risk of skin irritation or burns [17,20-22]. Yang et al. [19] carried out a microencapsulation study in which they used chitosan as a wall material, having observed that the microencapsulation process provided a controlled release when compared to free methyl salicylate.

In this context, the present study aims to evaluate the behavior of methyl salicylate microcapsules obtained by complex coacervation and incorporated in Jersey $100 \%$ cotton and $100 \%$ polyamide textile structures, using in vitro release profiles, and when subjected to washing at different temperatures.

\section{Materials and Methods}

The materials used for the development of the microcapsules were gelatin and gum Arabic (Sigma-Aldrich, São Paulo, SP, Brazil), methyl salicylate (Induslab, Londrina, PR, Brazil) as well as the sodium lauryl sulfate (Exodos, Sumaré, SP, Brazil). For the microcapsules cross-linking, glutaraldehyde (25\%) (Sigma-Aldrich, São Paulo, SP, Brazil). The materials used in the esterification of the finishing were citric acid (Synth, Diadema, SP, Brazil) and sodium hypophosphite (SHIP) (Sigma-Aldrich, São Paulo, SP, Brazil).

Jersey knits were used in the compositions of $100 \%$ cotton, with a weight of $280 \mathrm{~g} \mathrm{~m}^{-2}$, and $100 \%$ polyamide, with a weight of $200 \mathrm{~g} \mathrm{~m}^{-2}$, both produced at the Process Research Laboratory of the University of Minho, Guimarães, Portugal.

\subsection{Preparation of Microcapsules}

The preparation of the microcapsules was performed through the complex coacervation method based on the techniques presented in the works of Yang et al. [23], Butstraen and Salaün [24] and Bezerra et al. [25], which presented the use of biopolymers, $\mathrm{pH}$ adjustment and active principle.

Three different solutions were prepared, which used deionized water as a solvent, and placed in a thermostated bath at $40^{\circ} \mathrm{C}$. The first solution was constituted by dissolving $3 \mathrm{~g}$ of gelatin in $50 \mathrm{~mL}$ of solution, subjected to magnetic stirring at $300 \mathrm{rpm}$ for $15 \mathrm{~min}$. The second emulsion was composed of $0.3 \mathrm{~g}$ of sodium lauryl sulfate and $3 \mathrm{~mL}$ of methyl salicylate in $50 \mathrm{~mL}$ of solution, under stirring at $300 \mathrm{rpm}$ for $15 \mathrm{~min}$. Finally, the third solution was prepared by inserting $3 \mathrm{~g}$ of gum Arabic into $100 \mathrm{~mL}$ of water, under magnetic stirring at $300 \mathrm{rpm}$ for $15 \mathrm{~min}$. Subsequently, the methyl salicylate solution was added dropwise to the gelatin solution to form a colloidal emulsion system with the active ingredient, which was mechanically stirred at $500 \mathrm{rpm}$ for $10 \mathrm{~min}$. The insertion of the third solution was also performed dropwise, in order to ensure a slow interaction between the biopolymers. Stirring occurred at $700 \mathrm{rpm}$ for $10 \mathrm{~min}$. In order to ensure the reaction between gelatin and gum Arabic, positive and negative polyelectrolyte, the $\mathrm{pH}$ was adjusted with $5 \mathrm{~mol} \mathrm{~L}^{-1}$ 
citric acid to $\mathrm{pH}$ 4.1, which fits into what was discussed by Duhoranimana et al. [26] as the best interaction range, namely $\mathrm{pH}$ 4.0-4.5. The solution was stirred for $90 \mathrm{~min}$.

For the gelation process, the solution was cooled to a range of 0 to $8{ }^{\circ} \mathrm{C}$ and kept under stirring for $60 \mathrm{~min}$. After this process, the microcapsules were cross-linked with $0.5 \mathrm{~g}$ glutaraldehyde (25\%), which was added to the solution after it was adjusted to $\mathrm{pH} 8-9$ with $\mathrm{NaOH} 1 \mathrm{~mol} \mathrm{~L}^{-1}$ and kept under stirring at $700 \mathrm{rpm}$ for $30 \mathrm{~min}$.

The microcapsules were kept in solution to promote greater impregnation of methyl salicylate in the textile substrates, as the active ingredient that has not been encapsulated may also be deposited on the surface of the textile article.

\subsection{Characterization of the Microcapsules}

The interaction of the polymers for the production of microcapsules was evaluated by FTIR (Nicolet Avatar, Golden Valey, MN, USA), in the range of 4000 to $500 \mathrm{~cm}^{-1}$. For thermal stability (TG), the test was performed at a speed of $10{ }^{\circ} \mathrm{C} \mathrm{min}^{-1}$, in the temperature range of $30{ }^{\circ} \mathrm{C}$ to $800{ }^{\circ} \mathrm{C}$ in a nitrogen atmosphere with a flow of $50 \mathrm{~mL}$ $\min ^{-1}$ (Shimadzu, model TG-50,Tokyo, Japan). The morphology and structure of the microcapsules were evaluated by SEM (Quanta 250, Hillsboro, OR, USA).

\subsection{Functionalization of Textile Substrates}

The functionalization of the textile substrates occurred by esterification with citric acid and application of the microcapsules. The application of microcapsules was performed through the pad-dry-cure process, followed by a drying process at $80^{\circ} \mathrm{C}$ for $3 \mathrm{~min}$ and, subsequently, the cure was performed at $120^{\circ} \mathrm{C}$ for $2 \mathrm{~min}$, a technique that has been adapted from the work of Rodrigues et al. [27], Azizi et al. [28] and Nada et al. [29].

The textile articles, cotton and polyamide, were impregnated for $1 \mathrm{~min}$ in a solution of microcapsules $\left(30 \mathrm{~g} \mathrm{~L}^{-1}\right)$, citric acid $\left(30 \mathrm{~g} \mathrm{~L}^{-1}\right)$ and sodium hypophosphite $\left(10 \mathrm{~g} \mathrm{~L}^{-1}\right)$ at $25{ }^{\circ} \mathrm{C}$ and $\mathrm{pH} 6$, and subsequently, the samples were taken to the foulard process. The pick-up adopted was $80 \%$.

\subsection{Evaluation of the Functionalization of Textile Substrates}

To evaluate the chemical modification on the surface of the textile substrates after the functionalization with microcapsules, this study used the Fourier transform infrared spectroscopy technique in the infrared region with attenuated reflectance (FTIR/ATR), in the range between 4000 to $600 \mathrm{~cm}^{-1}$. The surface of the textile articles, untreated and treated with microcapsules, was analyzed by scanning electron microscopy.

The study of the in vitro controlled release of methyl salicylate from cotton and polyamide substrates was performed in triplicate. The functionalized samples were sent to a water and ethanol $(2: 1 \mathrm{v} / \mathrm{v})$ bath thermostated at $37^{\circ} \mathrm{C}$ under stirring in a shaker (Solab, Piracicaba, SP, Brazil). At predetermined times, aliquots were taken and filtered, to determine the absorbances in the wavelength of methyl salicylate at $306 \mathrm{~nm}$, by the UV-Vis technique (Shimadzu, Tokyo, Japan).

The functionalized textile samples were subjected to the washing test with procedure adapted from the Standard AATCC 61-2007-2A (Colorfastness to Laundering: Accelerated). They were inserted into mugs (Kimak, Brusque, SC, Brazil) under the following conditions: $50 \mathrm{~mL}$ of solution with steel balls for $45 \mathrm{~min}$, the temperature varying between 37 and $50{ }^{\circ} \mathrm{C}$. At each wash cycle, aliquots were taken and filtered to determine the amount of methyl salicylate by absorbance in the spectrophotometer in the ultraviolet region (UV-Vis).

\section{Results and Discussion}

\subsection{Evaluation of the Functional Groups of the Microcapsules (FTIR)}

The interactions of the polymers used for the formation of the microcapsules were evaluated by the FTIR technique. Figure 1 shows the spectrograms of the microcapsules that were obtained, as well as those of the wall materials, gelatin and gum Arabic and of the active ingredient methyl salicylate. 


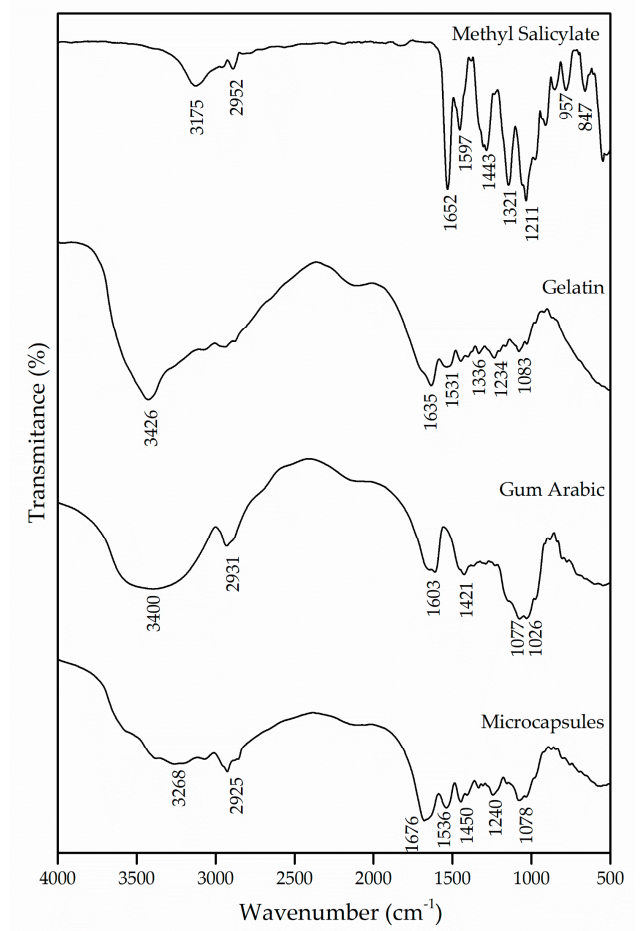

Figure 1. Infrared spectroscopy (FTIR) of methyl salicylate, gelatin and gum Arabic and the microcapsules obtained.

Methyl salicylate has in its molecule intramolecular hydrogen bonds between hydroxyl and carbonyl groups [20]. The bands in the regions of $3175 \mathrm{~cm}^{-1}$ and $2952 \mathrm{~cm}^{-1}$ are attributed to the hydroxyl group and the asymmetrical stretching of the $\mathrm{CH}_{2}$, respectively. The band at $1652 \mathrm{~cm}^{-1}$ was derived from the existence of $\mathrm{C}=\mathrm{O}$ stretching vibrations of the carboxylic acid group [30]. Likewise, the bands in the regions of $1597 \mathrm{~cm}^{-1}$ and $1443 \mathrm{~cm}^{-1}$ appear due to the asymmetrical and symmetrical stretching of the deprotonated carboxylate group, respectively [31].

The gelatin, being a protein, is characterized by amide and amine groups in its chemical structure. The absorption band in the region of $3426 \mathrm{~cm}^{-1}$ corresponds to the vibrations of the amino functional groups $\mathrm{N}-\mathrm{H}[29,32,33]$. The $\mathrm{C}=\mathrm{O}$ stretching of peptide bonds and the deformation of the $\mathrm{N}-\mathrm{H}$ were identified in the band of $1635 \mathrm{~cm}^{-1}$, which refers to the region of the amide I [34-36]. Another absorption characteristic of the gelatin occurs in the region of $1531 \mathrm{~cm}^{-1}$, which can be attributed to the amide II due to the flexion of the groups $\mathrm{N}-\mathrm{H}$ and the stretching of $\mathrm{C}-\mathrm{N}[36,37]$. The absorption of the band in the region of $1234 \mathrm{~cm}^{-1}$ is caused by the stretching vibration of the groups $\mathrm{N}-\mathrm{H}$ and $\mathrm{C}-\mathrm{N}$, corresponding to the amide III [38].

The gum Arabic has in its chemical structure carboxylic groups, which justifies the presence of negative charges. The bands at $1603 \mathrm{~cm}^{-1}$ and $1421 \mathrm{~cm}^{-1}$ are derived from the asymmetric and symmetric stretching vibration of carboxylic acid $\left(-\mathrm{COO}^{-}\right)$, respectively, which is attributed to the carboxylate groups of the glucuronic acid present in the gum Arabic [39-42]. To represent the elongation of the $\mathrm{C}-\mathrm{O}$ bond, bands were detected in the regions of $1077 \mathrm{~cm}^{-1}$ and $1026 \mathrm{~cm}^{-1}$. Similar results were found by [40,43-45].

For the interaction of biopolymers to occur and for the formation of microcapsules, it is essential that both the protein and the polysaccharide have oppositely charged side groups that will allow interaction between them, promoting the coacervation process and the formation of amides. The spectrum of the microcapsules was compared with that of the wall materials, and a shift of the amide I and amide II bands from $1635 \mathrm{~cm}^{-1}$ and $1531 \mathrm{~cm}^{-1}$ to $1676 \mathrm{~cm}^{-1}$ and $1536 \mathrm{~cm}^{-1}$ can be observed, which, according to the authors Shaddel et al. [34], García-Saldaña et al. [35] and Shaddel et al. [46], evidences the generation of an electrostatic interaction between the positively charged amine groups 
of gelatin $\left(\mathrm{NH}_{3}^{+}\right)$and the negatively charged carboxylic groups of gum Arabic $\left(\mathrm{COO}^{-}\right)$. Such interaction can also be confirmed with the emergence of the band in the region of $1450 \mathrm{~cm}^{-1}$, which indicates the presence of an amide, corroborating the formation of this complex $[43,46]$. Based on this, it can be assumed that the wall materials of the microcapsule participated in the microencapsulation process by electrostatic interaction and that hydrogen bonds were also involved in the coacervation of the biopolymers.

\subsection{Thermal Stability (TG/dTG)}

The thermal stability of the microcapsules was evaluated by thermogravimetric curves (TG) and the curves of the first derivative of the thermogravimetric curve (dTG) with respect to time, as shown in Figure 2a,b, respectively.

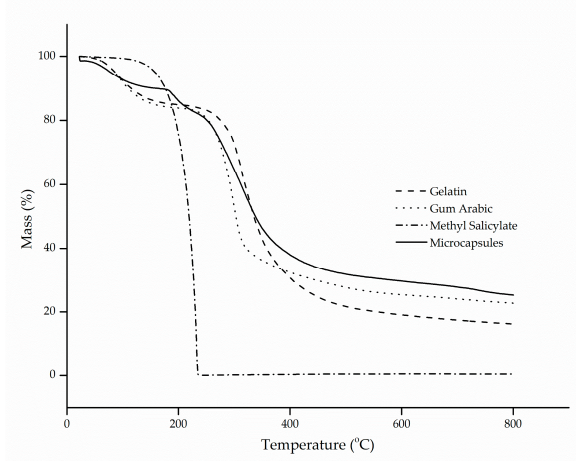

(a)

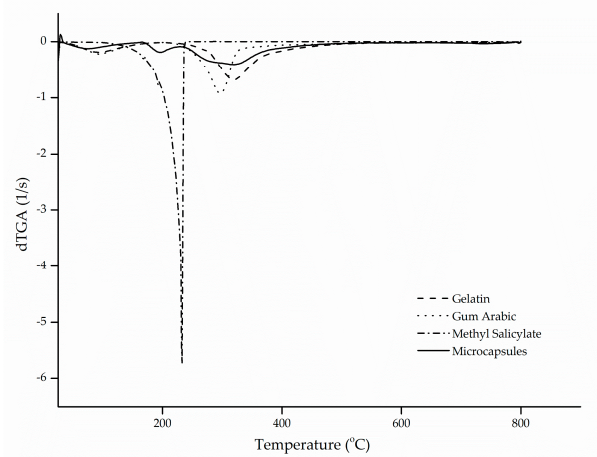

(b)

Figure 2. (a) thermal stability (TG) and (b) thermogravimetric curve (dTG) of gelatin, gum Arabic, methyl salicylate and microcapsules.

The thermogram of methyl salicylate showed only one stage of mass loss, in a configuration similar to a parabola, which starts at approximately $100^{\circ} \mathrm{C}$ until full evaporation at $218^{\circ} \mathrm{C}$, a characteristic common to oils and fragrances. This phenomenon is confirmed by the evaporation temperature of the active ingredient, which is in the range of 220 to $224^{\circ} \mathrm{C}[47]$.

Gelatin and gum Arabic followed similar and characteristic thermal degradation profiles, in which two stages of decomposition were presented [7,29]. The first stage is associated with the hydrolysis of the polymer chain, that is, the release of water bound to the hydrophilic groups of the polymers [48,49], which showed a mass loss of approximately $15.9 \%(\mathrm{~m} / \mathrm{m})$, corresponding to the maximum peak temperature at $92{ }^{\circ} \mathrm{C}$. The second stage represents the breakdown of the molecular chains of the protein and the polysaccharide $[50,51]$, at temperatures of 318 and $296^{\circ} \mathrm{C}$, in that order.

As for the microcapsules, it can be observed that the behavior of thermal degradation occurred in three stages, as was also observed by Matos et al. [52]. The first degradation stage, with a maximum temperature of $60^{\circ} \mathrm{C}$, corresponded to a mass loss of $12.2 \%(\mathrm{~m} / \mathrm{m})$, which is related to the complete release of water linked to the structure of the microcapsules and to the evaporation of the methyl salicylate present on the surface of the microcapsules. The second mass loss corresponds to the second stage, which suffered a faster decline, and it can be explained by the rapid release of the active compound due to the high volatility of the material, together with the decomposition of the protein and the polysaccharide used as the wall material. This resulted in a significant mass reduction of approximately $42 \%$ $(\mathrm{m} / \mathrm{m})$, at a temperature in the range of $324^{\circ} \mathrm{C}$. Complete degradation of the biopolymers occurred in the third stage, at $584{ }^{\circ} \mathrm{C}$, with a mass reduction of $38.7 \%(\mathrm{~m} / \mathrm{m})[7,22,52,53]$.

The results presented above confirm that the encapsulation of methyl salicylate by complex coacervation microcapsules can significantly improve the thermal stability of the active compound, suggesting that it was actually encapsulated. 


\subsection{Morphology (MEV)}

Figure 3 shows the morphology and structure of the microcapsules. According to the micrograph presented, it can be seen that the complex coacervation process formed microcapsules with well-defined geometry in the shape of elongated spheres, as shown in the Muhoza et al. [54] that used the complex coacervation technique, with distribution of the polydisperse material and with a dispersion slightly affected by agglomerates. According to Alvim and Grosso [55], glutaraldehyde cross-linked microcapsules tend to come together during the drying process, as the glutaraldehyde is heat activated, and the aldehydes not bound to amino groups can be polymerized during the drying process. However, this shape is not a problem for this work since the elongated spheres can be deposited on the fabric surface, as well as the regular spheres. The difference in surface area of the microcapsules allows some of them to be deposited in different regions of the fiber.

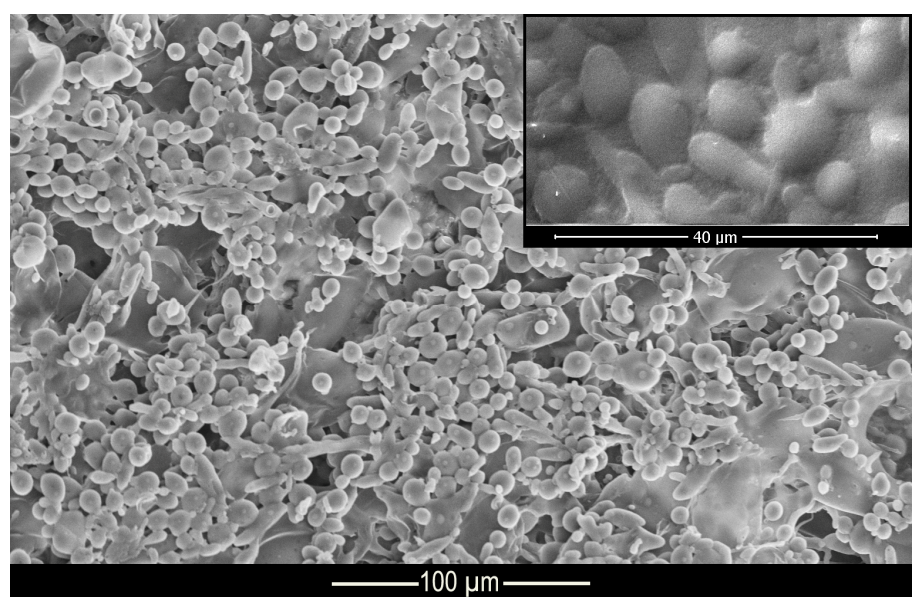

Figure 3. Micrograph of methyl salicylate microcapsules.

\subsection{Functionalization of Textile Substrates}

The chemical modification of the textile substrates was evaluated by FTIR-ATR, which allowed the detection of the presence of functional groups in the molecular structure of cotton and polyamide fibers, untreated and treated with the microcapsules of methyl salicylate, as shown in Figure 4.

Comparing the spectra of the untreated cotton with those from the treated samples, the appearance of the bands in the region of $1633 \mathrm{~cm}^{-1}$ and $1529 \mathrm{~cm}^{-1}$, characteristic of secondary amide, can be observed, which shows a new molecular interaction between the microcapsules and the cotton fabric. Similar results were found by Bezerra et al. [25], which verified the effectiveness of the finishing by the appearance of the band at $1540 \mathrm{~cm}^{-1}$ in the cotton fabric, subsequent to the incorporation of the gelatin and gum Arabic microcapsules.

It can also be noted that there was the appearance of the band at $1726 \mathrm{~cm}^{-1}$, which is related to the esterification between the hydroxyl groups present in the microcapsule, the carboxylic groups of citric acid and the hydroxyl group of cellulose $[28,55]$. The esterification reaction allows the microcapsule to incorporate into the fiber, thus making the finishing more resistant to washing, as this is one of the limiting factors for fabric finishing.

The spectra of the polyamide samples before and after the finishing are shown in Figure $4 \mathrm{~b}$. The treated polyamide samples did not show to be different due to the overlapping of the bands of the microcapsules with the functional groups of the polyamide. Once again, the appearance of the band in the region of $1729 \mathrm{~cm}^{-1}$, which represents the carbonyl group of the ester group, could be observed as a result of the chemical interaction of citric acid between the microcapsules and the polyamide. 


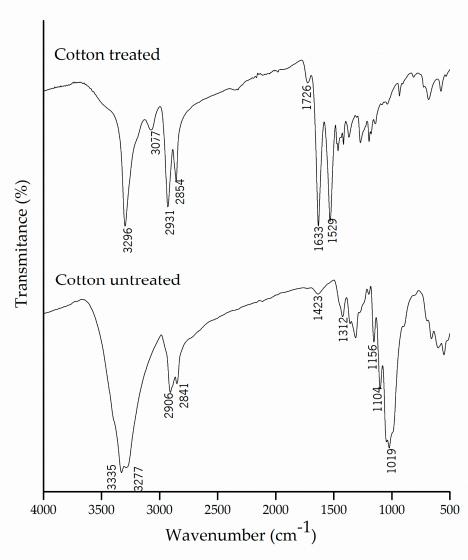

(a)

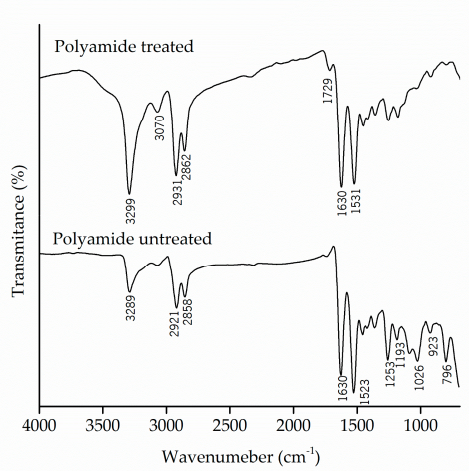

(b)

Figure 4. Infrared spectrum with attenuated reflectance (FTIR/ATR) of pure and treated (a) cotton and (b) polyamide substrates.

\subsection{Quantification and Controlled Release of Methyl Salicylate}

The study of the release profile of an active compound from polymeric systems is important to understand its behavior and the mechanism by which release occurs. To better understand and evaluate the release of methyl salicylate, mathematical models were adopted to adjust the release system, and the selected models were Higuchi [56] and Korsmeyer-Peppas et al. [57].

Figure $5 \mathrm{a}, \mathrm{b}$ presents the in vitro release profiles for cotton and polyamide samples, respectively. For both samples, it can be observed that the methyl salicylate, when freely impregnated into the textile structure, was completely released in approximately $60 \mathrm{~min}$, reaching $98 \%$ of the released compound. Regarding the samples functionalized with microcapsules, the results showed release profiles in two stages: a rapid initial release (burst effect), followed by a slower increase until the equilibrium, in which the maximum amount of methyl salicylate released is reached after $250 \mathrm{~min}$ for cotton and $350 \mathrm{~min}$ for polyamide. Similar behaviors were found in the works of Ma et al. [58], Aguiar et al. [59] and Macha et al. [60]. The first release step may be explained by the release of the methyl salicylate that was on the surface of the textile substrate due to the method of application, that is, the part of the active compound that was not coated by the microcapsules [60].

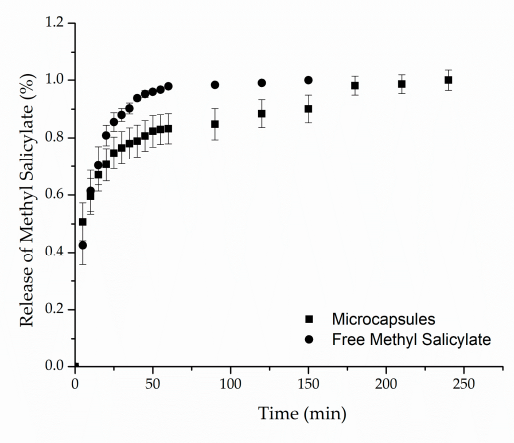

(a)

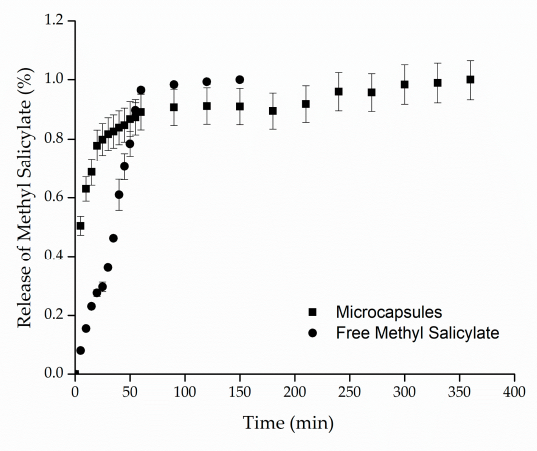

(b)

Figure 5. In vitro release profile of methyl salicylate from (a) cotton and (b) polyamide textile. 
The kinetic adjustments of the profiles of controlled release from samples of cotton and polyamide, considering the first $80 \%$ of release of the active ingredient [61], are presented in Figures 6 and 7.

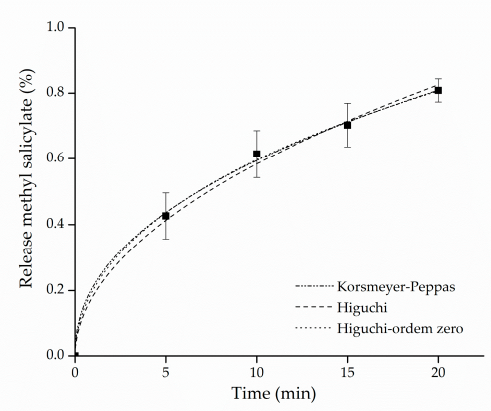

(a) CO untreated

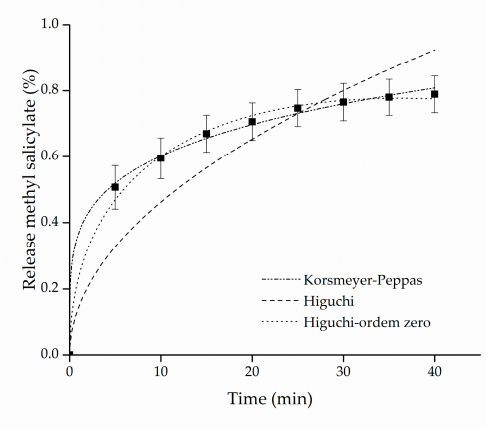

(b) CO treated

Figure 6. Kinetic adjustments of the profiles of controlled release from (a) cotton (CO) untreated and (b) CO treated.

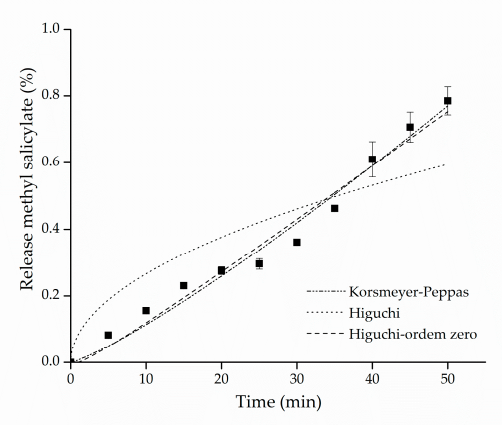

(a) PA untreated

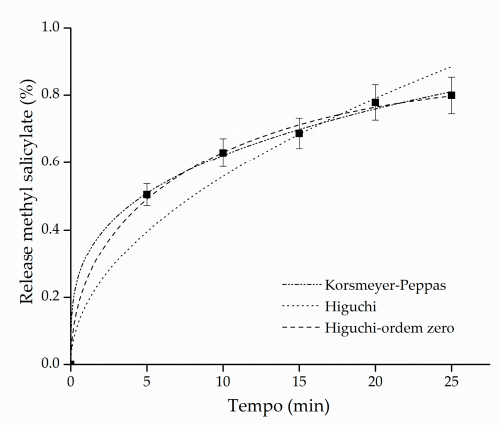

(b) PA treated

Figure 7. Kinetic adjustments of the profiles of controlled release from (a) polyamide (PA) untreated and (b) PA treated.

The adjustment that best represented the release of both cotton and polyamide samples was the model proposed by Korsmeyer-Peppas. This model provides information about the release mechanism, which is evaluated using exponent $n$, as shown in Table 1 .

Table 1. Interpretation of the release mechanisms from polymeric systems, as proposed by KorsmeyerPeppas et al. [57].

\begin{tabular}{cccc}
\hline Surface & Cylinder & Sphere & Diffusion Mechanism \\
\hline 0.5 & 0.45 & 0.43 & Fickian \\
$0.5<n<1.0$ & $0.45<n<0.89$ & $0.43<n<0.85$ & Anomalous \\
1.0 & 0.89 & 0.85 & Non-Fickian \\
\hline
\end{tabular}

The parameters of the mathematical adjustments are presented in Table 2, and it is possible to observe that as regards the cotton sample with free methyl salicylate, the value of $n=0.44527 \pm 0.02458$ was obtained, whereas for the sample functionalized with microcapsules, the value of $n=0.22322 \pm 0.00959$ was obtained. According to the values of $n$ presented in Table 1, both profiles indicate Fickian diffusion, caused by the degree of swelling of the matrices, which is determined by the high mobility of the polymer chains of the polymers forming the microcapsules and by the cotton fiber chains [61,62]. Other studies have also reported values of $n$ lower than 0.43 for spherical polymer systems. 
This assumes that a reduction of this variable can be expected when the release study occurs by polydisperse systems with irregular geometries, indicating, nevertheless, the presence of Fickian mechanism [63,64].

Table 2. Parameters of the mathematical adjustments for the models of Korsmeyer-Peppas, Higuchi and Higuchi zero-order.

\begin{tabular}{cccc}
\hline Model & Parameter & CO Untreated & CO Treated \\
\hline \multirow{3}{*}{ Higuchi zero-order } & $\mathrm{R}^{2}$ & 0.99831 & 0.99507 \\
& $\mathrm{~K}_{0}\left(10^{-2}\right)$ & $-0.00642 \pm 0.00259$ & $-0.02134 \pm 0.00126$ \\
& $\mathrm{~K}_{\mathrm{HO}}$ & $0.2091 \pm 0.01003$ & $0.25751 \pm 0.0067$ \\
\hline \multirow{2}{*}{ Higuchi } & $\mathrm{R}^{2}$ & 0.99614 & 0.81856 \\
& $\mathrm{~K}_{\mathrm{H}}$ & $0.18465 \pm 0.00279$ & $0.14612 \pm 0.00793$ \\
\hline \multirow{3}{*}{ Korsmeyer-Peppas } & $\mathrm{R}^{2}$ & 0.99803 & 0.99741 \\
& $\mathrm{~K}_{\mathrm{KP}}$ & $0.2132 \pm 0.01392$ & $0.3687 \pm 0.011287$ \\
& $\mathrm{n}$ & $0.44527 \pm 0.02458$ & $0.2128 \pm 0.01106$ \\
\hline \multirow{3}{*}{ Higuchi zero-order } & & PA Untreated & PA Treated \\
& $\mathrm{R}^{2}$ & 0.95992 & 0.99712 \\
& $\mathrm{~K}_{0}\left(10^{-2}\right)$ & $0.01367 \pm 0.00271$ & $-0.02178 \pm 0.00228$ \\
& $\mathrm{~K}_{\mathrm{HO}}$ & $0.000066 \pm 0.01441$ & $0.26836 \pm 0.00975$ \\
\hline \multirow{2}{*}{ Higuchi } & $\mathrm{R}^{2}$ & 0.83729 & 0.94503 \\
& $\mathrm{~K}_{\mathrm{H}}$ & $0.07143 \pm 0.00567$ & $0.1768 \pm 0.00805$ \\
\hline \multirow{2}{*}{ Korsmeyer-Peppas } & $\mathrm{R}^{2}$ & 0.96041 & 0.99802 \\
& $\mathrm{~K}_{\mathrm{KP}}$ & $0.01211 \pm 0.00491$ & $0.31986 \pm 0.01523$ \\
& $\mathrm{n}$ & $1.03572 \pm 0.11702$ & $0.28872 \pm 0.0171$ \\
\hline
\end{tabular}

For the polyamide sample with free salicylate, it can be observed that the value of the release exponent resulted in $n=1.0$, indicating a zero-order release mechanism, which can be explained by the hydrophobicity of the polyamide fibers that, in contact with water, have resistance to swelling and consequently to the relaxation of polymer chains, favoring the rapid release of methyl salicylate. On the other hand, as regards the polyamide fabric treated with the microcapsules, the Korsmeyer-Peppas adjustment presented a value of $n=0.28872$, which, according to what is shown in Table 1 , is represented by the Fickian diffusion mechanism, that is, the microcapsule protects the active principle allowing the longer release time, consequently extending the life cycle of the finishing.

In this context, the release mechanisms (the value of the exponent $n$ ) were found according to the textile matrix, indicating that the hydrophilicity/hydrophobicity of the fabric is a determining factor of it, as reported in the works of Bezerra et al. [25] and Arias et al. [9], when they used cotton and polyester as a textile matrix to support encapsulated compounds, and the substrates influence the system release mechanism. Therefore, the mechanism can be modified according to the textile matrix, the microcapsule and the active principle, but in all experiments, their positive influence on controlled release was clear.

\subsection{Durability of the Finishing}

The cotton and polyamide substrates treated with microcapsules and cross-linked with citric acid were subjected to washing tests at temperatures of 37 and $50{ }^{\circ} \mathrm{C}$ with the procedure adapted from the Standard AATCC 61-2007-2A. Figure 8 shows the release profiles of the microcapsules against the number of wash cycles. Based on these data, it can be seen that the samples presented a high resistance to washing, showing an increase in the durability of the finishing.

Cross-linking agents, such as citric acid or polycarboxylates, increase the fabric/ microcapsule interaction through the esterification reaction, as shown by the FTIR-ATR technique, making the finishing more resistant to washing, as observed in the work of 
Bezerra et al. [10], when they used BTCA as cross-linking agent in gelatin and gum Arabic microcapsules.

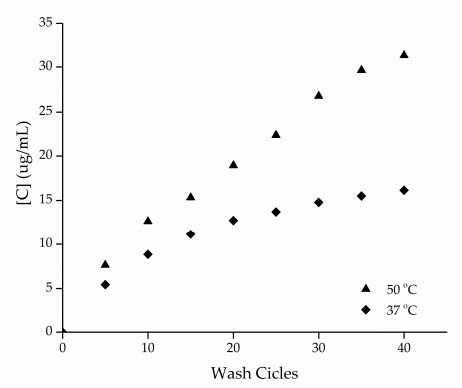

(a)

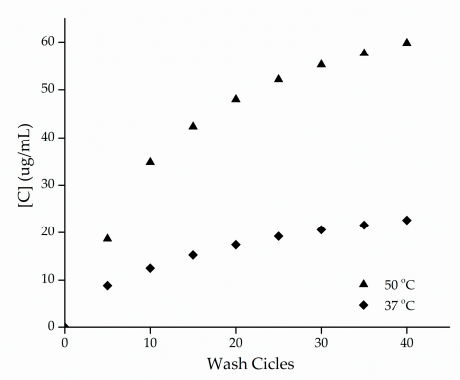

(b)

Figure 8. Release profile of methyl salicylate from samples of (a) cotton and (b) polyamide in the washing process.

Comparing the esterified samples washed at 37 and $50{ }^{\circ} \mathrm{C}$, the influence of temperature on the release of the active ingredient can be observed, since the samples washed at a temperature of $50{ }^{\circ} \mathrm{C}$ resulting in a greater release of methyl salicylate, which can be attributed to the breakdown of the structure of the microcapsules. In the work of Sun et al. [14], the efficiency of the impregnation of porous microgels fixed on cotton fabrics via citric acid cross-linking reaction was evaluated, having been observed in the study that the release at $37^{\circ} \mathrm{C}$ was higher compared to the release at $25^{\circ} \mathrm{C}$, indicating that the temperature has an effect proportional to the release of the active ingredient, as observed.

These results indicate that the microcapsules were incorporated into the cotton and polyamide structures, since after 40 wash cycles, there were still microcapsules embedded into the substrates, as can be seen from the microscopy shown in Figures 9 and 10. These results are superior to those found by Ramya et al. [65] who, when evaluating the durability to washing for herb extract microcapsules, found that the microcapsules presented good resistance up to 30 wash cycles due to the sustained release of the encapsulated extracts.

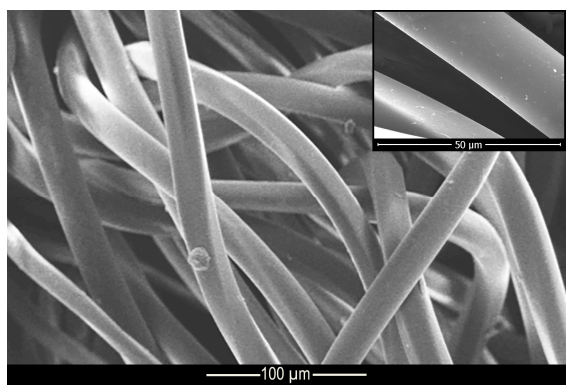

(a)

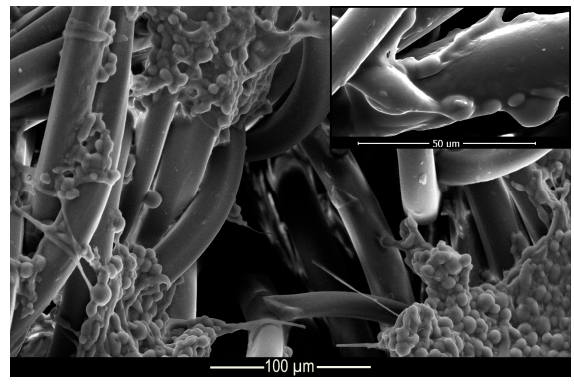

(b)

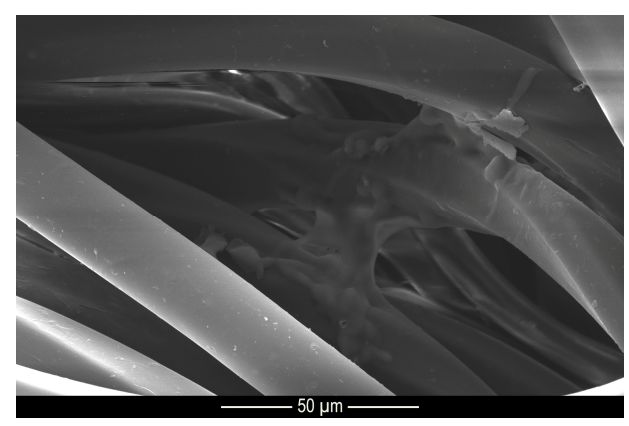

(c)

Figure 9. Microscopy of (a) untreated, (b) treated and (c) washed polyamide samples. 


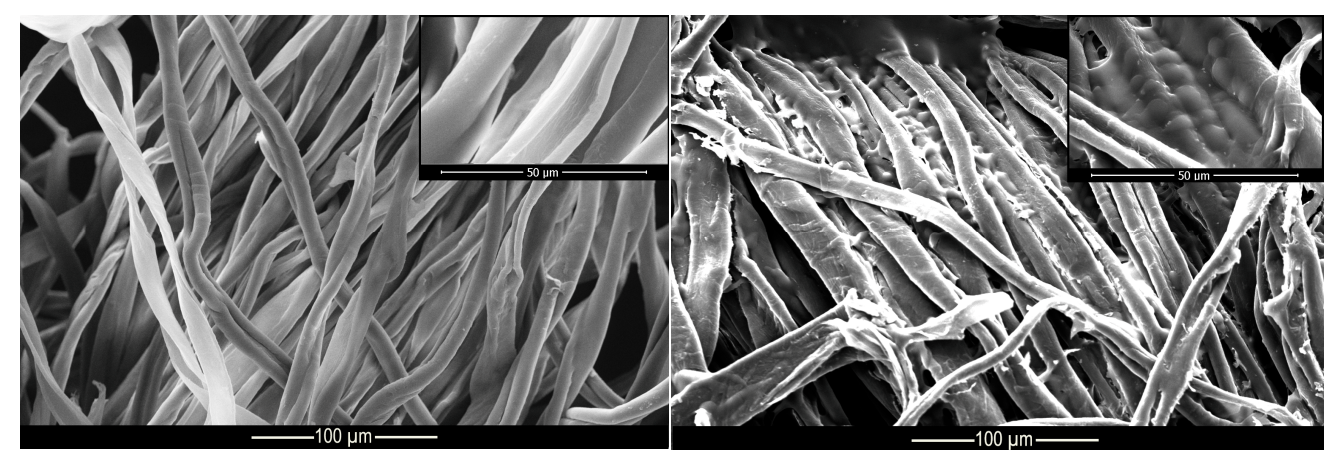

(a)

(b)

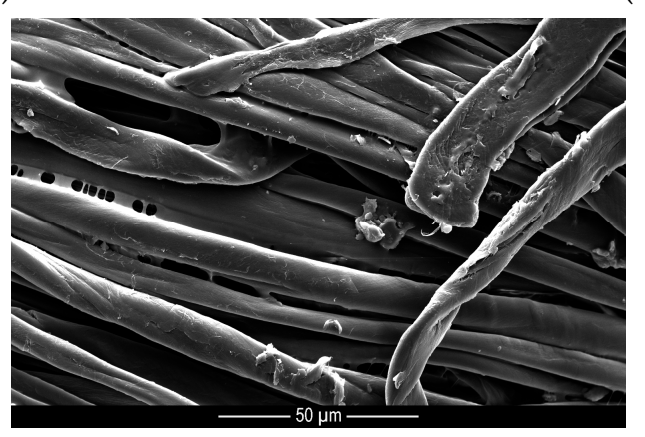

(c)

Figure 10. Microscopy of (a) untreated, (b) treated and (c) washed cotton samples.

\section{Conclusions}

By observing the results presented, it can be seen that methyl salicylate microcapsules produced by complex coacervation using gelatin and gum Arabic as wall materials were obtained. The shape of the microcapsules presented a well-defined geometry and good dispersion; furthermore, the thermal stability of the active material improved significantly with the microencapsulation process, that is, the compound obtained withstands temperatures above those at which the free active ingredient resists. The microcapsules incorporated into the fabrics release the active ingredient in a controlled manner, according to the adjustment made by the Korsmeyer-Peppas model, and also presented a high resistance to washing, since the release of methyl salicylate was lower in these samples when compared to simply depositing the microcapsules. The influence of temperature was also visible since, when subjected to the washing process at higher temperatures, namely $50{ }^{\circ} \mathrm{C}$, the release was more pronounced than at $37^{\circ} \mathrm{C}$.

In view of the aforementioned facts, the functionalization of cotton and polyamide substrates with methyl salicylate microcapsules can be considered as a promising alternative for the development of functional textile articles that will contribute to consumer welfare, due to the results of the microencapsulation and finishing durability.

Author Contributions: Conceptualization, S.M.; Formal analysis, N.F.; Investigation, S.M.; Methodology, F.M.B.; Project administration, A.C.; Supervision, A.C. and N.F.; Visualization, A.Z.; Writingoriginal draft, S.M. and F.M.B.; Writing-review \& editing, A.Z. All authors have read and agreed to the published version of the manuscript.

Funding: This work is supported by Project UID/CTM/00264/2019 of 2C2T - Centro de Ciência e Tecnologia Têxtil, funded by National Founds through FCT/MCTES.

Conflicts of Interest: The authors declare no conflict of interest. 


\section{References}

1. Kaur, R.; Kukkar, D.; Bhardwai, S.K.; Kim, K.H.; Deep, A. Potential use of polymers and their complexes as media for storage and delivery of fragrances. J. Control. Release 2018, 285, 81-95. [CrossRef] [PubMed]

2. Cheng, S.Y.; Yuen, C.W.M.; Kan, C.W.; Cheuk, K.K.L. Development of cosmetic textiles using microencapsulation technology. RJTA 2008, 12, 41-51. [CrossRef]

3. Prata, A.S.; Grosso, C.R.F. Production of microparticles with gelatin and chitosan. Carbohydr. Polym. 2015, 116, 292-299. [CrossRef] [PubMed]

4. Silva, P.T.; Frie, L.L.; Menezes, C.R.; Holkem, A.T.; Schwan, C.L.; Wigmann, E.F.; Bastos, J.O.; Silva, C.B. Microencapsulations: Concepts, mechanisms, methods and some applications in food technology. Ciênc. Rural. 2014, 44, 1304-1311. [CrossRef]

5. $\quad$ Das, S.K.; Davis, S.R.N.; Rajabalaya, R.; Mukhopadhyay, H.K.; Halder, T.; Palanisamy, M.; Khanam, J.; Nanda, A. Microencapsulation techniques and its practice. Int. J. Pharma. Sci. Tech. 2011, 6, 1-23.

6. Timilsena, Y.P.; Akanbi, T.O.; Khalid, N.; Adhikari, B.; Barrow, C.J. Complex coacervation: Principles, mechanisms and applications in microencapsulation. Int. J. Bio. Macromol. 2018, 1-53. [CrossRef]

7. Cruz, M.C.R.; Dagostin, J.L.A.; Perussello, C.A.; Masson, M.L. Assessment of physicochemical characteristics, thermal stability and release profile of ascorbic acid microcapsules obtained by complex coacervation. Food Hydrocoll. 2019, 87, 71-82. [CrossRef]

8. Hasanvad, E.; Rafe, A. Development of vanillin/ $\beta$-cyclodextrin inclusion microcapsules using flax seed gum-rice bran protein complex coacervates. Int. J. Bio. Macromol. 2019, 131, 60-66. [CrossRef]

9. Arias, M.J.L.; Coderch, L.; Martí, M.; Alonso, C.; Carmona, O.C.; Carmona, C.o.; Maesta, F. Vehiculation of active principles as a way to create smart and biofunctional textiles. Materials 2018, 11, 2152. [CrossRef]

10. Bezerra, F.M.; Lis, M.; Carmona, O.G.; Carmona, C.G.; Moisés, M.P.; Zanin, G.M.; Moraes, F.F. Assessment of the delivery of citronella oil from microcapsules supported on wool fabrics. Powder Technol. 2019, 343, 775-782. [CrossRef]

11. Carreras, N.; Acuña, V.; Martí, M.; Lis, M.J. Drug reléase system of ibuprofen in PCL-microespheres. Colloid Polym. Sci. 2013, 291, 157-165. [CrossRef]

12. Rubio, L.; Alonso, C.; Coderch, L.; Parra, J.L.; Martí, M.; Cebrián, J.; Navarro, J.A.; Lis, M.; Valldeperas, J. Skin delivery of caffeine contained in biofunctional textiles. Text. Res. J. 2010, 80, 1214-1221. [CrossRef]

13. Fiedler, J.O.; Carmona, O.G.; Carmona, C.G.; Lis, M.J.; Plath, A.M.S.; Samulewski, R.B.; Bezerra, F.M. Application of Aloe vera microcapsules in cotton nonwovens to obtain biofunctional textiles. J. Text. Inst. 2019, 1, 68-74. [CrossRef]

14. Sun, X.; Wang, X.; Wu, J.; Li, S. Development of thermosensitive microgel-loaded cotton fabric for controlled drug release. Appl. Surf. Sci. 2017, 403, 509-518. [CrossRef]

15. Guan, Y.; Zhang, L.; Wang, D.; West, J.L.; Fu, S. Preparation of thermochromic liquid crystal microcapsules for intelligent functional fiber. Mater. Des. 2018, 147, 28-34. [CrossRef]

16. Todorova, S.B.; Silva, C.J.S.; Simeonov, M.P.; Cavaco-Paulo, A. Cotton fabric: A natural matrix suitable for controlled release systems. Enzym. Microb. Technol. 2007, 40, 1646-1650. [CrossRef]

17. Liang, X.; Chen, Y.; Jiang, X.; Wang, S.; Zhang, J.; Gui, S. $\mathrm{H}_{\mathrm{II}}$ mesophase as a drug delivery system for topical application of methyl salicylate. Eur. J. Pharm. Sci. 2017, 100, 155-162. [CrossRef]

18. Kanagasabapathy, M.K.; Ramesh Bapu, G.N.K.; Umasankar, Y.; Gnanamuthu, R.M. Methyl salicylate detection via electrochemical transients using nano spinel $\mathrm{Co}_{3} \mathrm{O}_{4}$ films. J. Electroanal. Chem. 2015, 754, 57-64. [CrossRef]

19. Yang, Z.; Fang, Y.; Ji, H. Controlled release and enhanced antibacterial activity of salicylic acid by hydrogen bonding with chitosan. Chin. J. Chem. Eng. 2016, 24, 421-426. [CrossRef]

20. Victório, C.P.; Carriço, J.B.; Lage, C.L.S. Polygala paniculata: A source of methyl salicylate produced through plant tissue culture. Rev. Ceres. 2011, 58, 269-272. [CrossRef]

21. Varghese, H.T.; Panicker, C.Y.; Philip, D.; Mannekutla, J.R.; Inamdar, S.R. IR, Raman and SERS studies of methyl salicylate. Spectrochim. Acta Part A 2007, . 66, 959-963. [CrossRef]

22. Lapczynski, A.; Jones, L.; McGinty, D.; Bhatia, S.P.; Letizia, C.S.; Api, A.M. Fragrance material review on methyl salicylate. Food Chem. Toxicol. 2007, 45, S428-S452. [CrossRef]

23. Yang, Z.; Peng, Z.; Li, J.; Li, S.; Kong, L.; Li, P.; Wang, Q. Development and evaluation of novel flavour microcapsules containing vanila oil using complex coacervation approach. Food Chem. 2014, 145, 272-277. [CrossRef] [PubMed]

24. Butstraen, C.; Salaün, F. Preparation of microcapsules by complex coacervation of gum Arabic and chitosan. Carbohydr. Polym. 2014, 99, 608-616. [CrossRef] [PubMed]

25. Bezerra, F.M.; Carmona, O.G.; Carmona, C.G.; Lis, M.J.; Moraes, F.F. Controlled release of microencapsulated citronella essential oil on cotton and polyester matrices. Cellulose 2016, 23, 1459-1470. [CrossRef]

26. Duhoranimana, E.; Yu, J.; Mukeshimana, O.; Habinshuti, I.; Karangwa, E.; Xu, X.; Muhoza, B.; Xia, S.; Zhang, X. Thermodynamic characterization of gelatin-sodium carboxymethyl cellulose complex coacervation encapsulating Conjugated Linoleic Acid (CLA). Food Hydrocoll. 2018, 80, 149-159. [CrossRef]

27. Rodrigues, S.N.; Martins, I.M.; Fernandes, I.P.; Gomes, P.B.; Mata, V.G.; Barreiro, M.F.; Rodrigues, A.E. Scentfashion ${ }^{\circledR}$ : Microencapsulated perfumes for textile application. Chem. Eng. J. 2009, 149, 463-472. [CrossRef]

28. Azizi, N.; Chevalier, Y.; Majdoub, M. Isosorbide-based microcapsules for cosmeto-textiles. Ind. Crop. Product. 2014, 52, 150-157. [CrossRef] 
29. Nada, A.; Al-Moghazy, M.; Soliman, A.A.F.; Rashwan, G.M.T.; Eldawy, T.H.A.; Hassan, A.A.E.; Sayed, G.H. Pyrazole-based compounds in chitosan liposomal emulsion for antimicrobial cotton fabrics. Int. J. Bio. Macromol. 2018, 107, 585-594. [CrossRef]

30. Unal, B.; Kavas, D.H.; Baykal, A.; Toprak, M.S. Synthesis, conductivity and dielectric characterization of salicylic acid-Fe ${ }_{3} \mathrm{O}_{4}$ nanocomposite. Mater. Chem. Phys. 2010, 123, 184-190. [CrossRef]

31. Yost, E.C.; Tejedor-Tejedor, M.I.; Anderson, M.A. In situ CIR-FTIR characterization off salicylate complexes at the goethite/aqueous solution interface. Environ. Sci. Technol. 1990, 24, 822-828. [CrossRef]

32. Voron'ko, G.; Derkach, S.R.; Kuchina, Y.A.; Sokolan, N.I. The chitosan-gelatin (bio)polyelectrolyte complexes formationin an acidic medium. Carbohydr. Polym. 2016, 138, 265-272. [CrossRef] [PubMed]

33. Qiao, M.; Ma, X.; Zhang, J.; Yao, J. Molecular interactions in gelatin/chitosan composite films. Food Chem. 2017, 235, 45-50. [CrossRef] [PubMed]

34. Shaddel, R.; Hesari, J.; Azadmard-Damirchi, S.; Hamishehkar, H.; Fathi-Achachlouei, B.; Huang, Q. Use of gelatin and gum Arabic for encapsulation of black raspberry anthocyanins by complex coacervation. Int. J. Bio. Macromol. 2018, 107, 1800-1810. [CrossRef] [PubMed]

35. García-Saldaña, J.S.; Campas-Baypoli, O.N.; López-Cervantes, J.; Sánchez-Machado, D.I.; Cantú-Soto, E.U.; Rodríguez-Ramírez, R.R. Microencapsulation of sulforaphane from broccoli seed extracts by gelatin/gum arabic and gelatin/pectin complexes. Food Chem. 2016, 201, 94-100. [CrossRef]

36. Roy, J.C.; Giraud, S.; Ferri, A.; Mossotti, R.; Jingpin, G.; Salaün, F. Influence of process parameters on microcapsule formation from chitosan - Type B gelatin complex coacervates. Carbohydr. Polym. 2018, 198, 281-293. [CrossRef]

37. Souza, V.B.; Thomazini, M.; Barrientos, M.A.E.; Nalin, C.M.; Ferro-Furtado, R.; Genovese, M.I.; Favaro-Trindade, C.S. Functional properties and encapsulation of a proanthocyanidin-rich cinnamon extract (Cinnamomum zeylanicum) by complex coacervation using gelatin and different polysaccharides. Food Hydrocoll. 2018, 77, 297-306. [CrossRef]

38. Li, X.; Jiang, G.; Yang, L.; Peng, S. Study of gelatin as biodegradable shale hydration inhibitor. Colloids Surfaces A 2018, 539, 192-200. [CrossRef]

39. Qian, Y.F.; Kui, H.Z.; Chen, F.; Ke, Q.F.; Mo, X.M. Cross-linking of gelatin and chitosan complex nanofibers for tissue-engineering scaffolds. J. Biosci. Sci. 2011, 22, 1099-1113. [CrossRef]

40. Espinosa-Andrews, H.; Sandoval-Catilha, O.; Vázquez-Torres, H.; Vernon-Carter, E.J.; Lobato-Calleros, C. Determination of the gum Arabic-chitosan interactions by fourier transform infrared spectroscopy and characterization of the microstructure and rheological features of their coacervates. Carbohydr. Polym. 2010, 79, 541-546. [CrossRef]

41. Li, Y.; Zhang, X.; Sun, N.; Wang, Y.; Lin, S. Formation and evaluation of casein-gum arabic cocaervates via pH dependent complexation using fast acidification. Int. J. Biol. Macromol. 2018, 120, 783-788. [CrossRef]

42. Wu, D.; Xu, J.; Chen, Y.; Yi, M.; Wang, Q. Gum Arabic: A promising candidate for the construction of physical hydrogels exhibiting highly stretchable, self-healing and tensility reinforcing performances. Carbohydr. Polym. 2018, 181, 167-174. [CrossRef] [PubMed]

43. Tan, C.; Xie, J.; Zhang, X.; Cai, J.; Xia, S. Polysaccharide-based nanoparticles by chitosan and gum arabic polyelectrolyte complexation as carriers for curcumin. Food Hydrocoll. 2016, 57, 236-245. [CrossRef]

44. Ali, A.; Ganie, S.A.; Mazumdar, N. A new studt of iodine complexes of axidized gum arabic: An interaction between iodine monochloride and aldehyde groups. Carbohydr. Polym. 2018, 180, 337-347. [CrossRef] [PubMed]

45. Hu, Q.; Wang, T.; Zhou, M.; Xue, J.; Luo, Y. Formation of redispersible polyelectrolyte complex nanoparticles from gallic acid-chitosan conjugate and gum arabic. Int. J. Biol. Macromol. 2016, 92, 812-819. [CrossRef] [PubMed]

46. Shaddel, R.; Hesari, J.; Azadmard-Damirchi, S.; Hamishehkar, H.; Fathi-Achachlouei, B.; Huang, Q. Double emulsion followes by complex coacervation as a promising method for protection of black raspberry anthocyanins. Food Hydrocoll. 2018, 77, 803-816. [CrossRef]

47. Comunian, T.A.; Thomazini, M.; Alves, A.J.G.; Junior, F.E.M.; Balieiro, J.C.C.; Favaro-Trindade, C.S. Microencapsulation of ascorbic acid by complex coacervation: Protection and controlled release. Food Res. Int. 2013, 52, 373-379. [CrossRef]

48. Zohuriaan, M.J.; Shokrolahi, F. Thermal studies on natural and modified gums. Polym. Test. 2004, 23, 575-579. [CrossRef]

49. Daoub, R.M.A.; Elmubarak, A.H.; Misran, M.; Hassan, E.A.; Osman, M.E. Characterization and functional properties of some natural Acacia gums. J. Saudi Soc. Agric. Sci. 2016, 17, 241-249. [CrossRef]

50. Farooq, M.; Sagbas, S.; Sahiner, M.; Siddiq, M.; Turk, M.; Aktas, N.; Sahiner, N. Synthesis, characterization and modification of Gum Arabic microgels for hemocompatibility and antimicrobial studies. Carbohydr. Polym. 2017, 156, 380-389. [CrossRef]

51. Cozic, C.; Picton, L.; Garda, M.; Marlhoux, F.; Cerf, D.L. Analysis of arabic gum: Study of degradation and water desorption processes. Food Hydrocoll. 2009, 23, 1930-1934. [CrossRef]

52. Matos, E.L.; Scopel, B.S.; Dettmer, A. Citronella essential oil microencapsulation by complex coacervation with leather waste gelatin and sodium alginate. J. Environ. Chem. Eng. 2018, 6, 1989-1994. [CrossRef]

53. Lv, Y.; Abbas, S.; Karangwa., F. Simplified optimization for microcapsule prepation by complex coacervation based on the correlation between coacervates and the corresponding microcapsule. J. Food Eng. 2012, 111, 225-233. [CrossRef]

54. Muhoza, B.; Xia, S.; Jibao, C.; Zhang, X.; Duhoranimana, E.; Su, J. Gelatin and pectin complex coacervates as carriers for cinnamaldehyde: Effect of pectin esterification degree on coacervate formation, and enhanced thermal stability. Food Hydrocoll. 2019, 87, 712-722. [CrossRef]

55. Alvim, I.D.; Grosso, C.R.F. Microparticles obtained by complex coacervation: Influence of the type of reticulation and the drying process on the release of the core material. Cienc. Tecnol. Aliment. 2010, 30, 1069-1076. [CrossRef] 
56. Higuchi, T. Mechanism of sustained-action medication. Theoretical analysis of rate of release of solid drugs dispersed in solid matrices. J. Pharm. Sci. 1963, 5, 1145-1149. [CrossRef]

57. Korsmeyer, R.W.; Gumy, R.; Doelker, E.; Buri, P.; Peppas, N.A. Mechanisms of solute release from porous hydrophilic polymers. Int. J. Pharm. 1983, 15, 25-35. [CrossRef]

58. Ma, Z.H.; Yu, D.G.; Branford-White, C.J.; Nie, H.L.; Fan, Z.X.; Zhu, L.M. Microencapsulation of tamoxifen: Application to cotton fabric. Colloids Surf. B Biointerfaces 2009, 69, 85-90. [CrossRef]

59. Aguiar, J.; Costa, R.; Rocha, F.; Estevinho, B.N.; Santos, L. Design of microparticles containing natural antioxidants: Preparation, characterization and controlled release studies. Powder Technol. 2017, 313, 287-291. [CrossRef]

60. Macha, I.J.; Muna, M.M.; Magere, J.L. In vitro study and characterization of cotton fabric PLA composite as a slow antibiotic delivery device for biomedical applications. J. Drug Deliv. Sci. and Technol. 2018, 43, 172-177. [CrossRef]

61. Saghazadeh, S.; Rinoldi, C.; Schot, M.; Kashaf, S.S.; Sharifi, F.; Jalilian, E.; Nuutila, K.; Giatsidis, G.; Mostafalu, P.; Derakhshandeh, H.; et al. Drug delivery systems and materials for wound healing applications. Adv. Drug Deliv. Rev. 2018, 127, 138-166. [CrossRef] [PubMed]

62. Lyra, M.A.M.; Soares-Sobrinho, J.L.; Brasileiro, M.T.; Roca, M.F.; Barraza, J.A.; Viana, O.S.; Rolim-Neto, P.J. Sistemas matriciais hidrofílicos e mucoadesivos para liberação controlada de fármacos. Lat. Am. J. Pharm 2007, 26, 784-793.

63. Lopes, C.M.; Lobo, J.M.S.; Costa, P. Formas farmacêuticas de liberação modificada: Polímeros hidofílicos. Rev. Bras. Ciênc. Farm. 2005, 41, 143-154. [CrossRef]

64. Vahabzadeh, F.; Zivdar, M.; Najafi, A. Microencapsulation of orange oil by complex cocaervation and its release behavior. IJE Trans. B Appl. 2004, 17, 333-342.

65. Ramya, K.; Maheshwari, V. Development of eco friendly mosquito repellent fabric finished with andrographis paniculata plant extracts. Int. J. Pharm. Pharm. Sci. 2014, 6, 115-117. 